\title{
HYPNOTHERAPY PADA PASIEN HEMODIALISIS YANG MENGALAMI CHRONIC SORROW
}

\author{
Widyasih Sunaringtyas, Diana Rachmania, Linda Ishariani
}

\author{
Prodi S1 Keperawatan STIKES Karya Husada Kediri \\ Email: sihwidya123@gmail.com
}

\begin{abstract}
ABSTRAK
Chronic sorrow merupakan kesedihan mendalam atau perasaan berduka yang sedang berlangsung akibat pengalaman kehilangan yang terjadi secara berulang. Perasaan sedih dan pengalaman kehilangan tersimpan dalam memori bawah sadar. Keadaan ini dapat dialami pada kasus kasus paliatif, salah satunya gagal ginjal kronis dengan tindakan invasive hemodialisis. Tujuan penelitian ini mengetahui pengaruh hypnotherapy terhadap chronic sorrow. Desain penelitian menggunakan quasy eksperiment dengan pendekatan pre test - post test with control group. Sampel adalah pasien hemodialisis yang mengalami chronic sorrow, terdiri dari 20 responden kelompok intervensi dan 20 responden kelompok control, dengan purphosive sampling sesuai kriteria inklusi. Instrument untuk pengambilan data menggunakan intrumen baku kendall chronic sorrow. Uji pengaruh Wilcoxon Sign Rank pada kelompok intervensi menujukkan hasil $\mathrm{p}$ value $=0,000(\mathrm{p}<0,05)$ artinya H1 diterima, terdapat pengaruh hypnotherapy terhadap chronic sorrow, dan pada kelompok kontrol diperoleh p value: 0,65 (p>0.05) sehingga H1 ditolak artinya tidak ada pengaruh hypnotherapy terhadap chronic sorrow. Uji beda menggunakan Mann Whitney antara kelompok intervensi dan kontrol sebelum perlakuan didapatkan $\mathrm{p}$ value $=0,075$ artinya tidak ada perbedaan, sedangkan setelah perlakuan di dapatkan $\mathrm{p}$ value: $0,00(\mathrm{p}<0,05)$ artinya terdapat perbedaan yang significant. Dari hasil pengujian statistik dapat disimpulkan bahwa hypnotherapy berpengaruh terhadap chronic sorrow. Hypnotherapy dapat menjangkau pikiran bawah sadar dengan cara membuka kritikal area sehingga dapat diberikan sugesti dalam menjalani hidup yang lebih damai, mensyukuri keadaan.
\end{abstract}

Kata Kunci: Chronic sorrow, hypnotherapy, hemodialisis

\begin{abstract}
Chronic sorrow is a deep sadness or feeling of grief that is ongoing due to the experience of loss that occurs repeatedly. Feelings of sadness and experiences of loss are stored in the subconscious memory. This situation can be experienced in palliative cases, one of them is chronic kidney failure with invasive hemodialysis. The purpose of this study is to determine the effect of hypnotherapy on chronic sorrow. The study design used quasy experiment with pre-post test with control group. Samples were hemodialysis patients who experienced chronic sorrow, consisting of 20 respondents in the intervention group and 20 respondents in the control group, with purposive sampling according to inclusion criteria. Instrument for data retrieval using standard instruments kendall chronic sorrow.
\end{abstract}


Wilcoxon Sign Rank test in the intervention group showed the results of $p$ value $=$ $0,000(p<0.05)$ meaning that there was an effect between pre and post test in intervention group. In the control group was obtained $p$ value: 1.00 ( $p>0.05$ ) meaning that there was no effect between pre and post in control group. Different test used Mann Whitney was obtained p value: 0.00 ( $p<0.05)$ meaning there was a significant difference between intervention and control group. From the results of statistical tests it can be concluded that hypnotherapy has an effect on chronic sorrow. Hypnotherapy can reach the subconscious mind by guiding someone to open critical areas so that suggestions can be given to live more peacefully and be grateful.

Keywords: Chronic sorrow, hypnotherapy, hemodialysis

\section{PENDAHULUAN}

Chronic sorrow merupakan keadaan dukacita akibat kehilangan yang dapat terjadi dan kambuh secara berkala dan berisiko terjadi secara progresif (Alligood, 2017). Manifestasi yang terjadi antara lain: distress psikologis, disorganisasi, gangguan neuroendokrin, marah, perilaku panik, perubahan pola mimpi, perubahan tingkat aktivitas, putus asa, ansietas, dan merasa kehilangan (NANDA-I, 2015). Keadaan ini dapat dialami pasien pada kasus paliatif, salah satunya penderita gagal ginjal kronis dengan tindakan hemodialisis. Tindakan ini dijalani dalam jangka panjang bahkan sampai seumur hidup. Keadaan ini menimbulkan efek secara fisik maupun psikologis. Efek fisik yang terjadi adalah rasa nyeri, gangguan tekanan darah, anemia, kekakuan otot, dan pembengkakan. Sedangkan efek psikologis antara lain stres, rasa takut, depresi, kecemasan, dan putus asa. Masalah depresi pada penderita gagal ginjal dengan tindakan dialysis 65 orang, 29 orang $(44,6 \%)$ mengalami depresi sedang (Sari, 2017). Penelitian howe menjelaskan dari 108 penderita gagal ginjal kronis dengan tindakan dialysis mengalami depresi 52 orang
$(48,1)$, stress 38 orang $(35,2 \%)$, kecemasan 55 orang $(50,9 \%)$ (Suparti, 2018).

Masalah psikologis pada penderita gagal ginjal dengan hemodialis terjadi mulai dari manifestasi ringan sampai mengalami kesedihan mendalam dan terjadi secara berulang, karena perasaan ini tersimpan pada memori bawah sadar. Masalah psikologis yang dialami oleh penderita memerlukan perhatian dan penanganan agar kondisi psikologis stabil sehingga sistem hormon dalam tubuh dan hemodinamik tubuh seimbang. Salah satu tindakan keperawatan komplementer untuk kasus ini, yang dapat menjadi solusi adalah hypnotherapy. Hypnotherapy merupakan terapi untuk mengatasi masalah psikologis, mampu menjangkau pikiran bawah sadar, sehingga dapat di berikan sugesti, re-edukasi, dan meyembuhkan pikiran. Hypnotherapy bermanfaat membantu mengatasi masalah trauma, ketakutan, stress, kecemasan maupun depresi.

Chronic sorrow yang dialami pasien gagal ginjal dengan hemodialisis yang dirasakan secara terus menerus tentu akan mengganggu ketenangan jiwanya. Dengan hipnoterapi maka penderita 
dibimbing melakukan relaksasi fisik dan mental, agar dapat memasuki area kritikal faktor. Pada keadaan ini baru diberikan sugesti agar dapat menjalani hidup dengan rasa syukur meskipun dalam kondisi sakit. Hal ini juga ditulis oleh dave elman seorang pakar hypnotherapy yang menyatakan masalah psikologis dapat diterapi dengan cara melakukan sugesti terhadap keyakinan hidup yang menyenangkan, tidak takut menghadapi perubahan dan lebih mampu menjalani hidup (Gunawan, 2007; Elman Dave, 1977). Tindakan ini mempunyai efek yang cukup permanen, sehingga manfaat yang dirasakan klien dirasakan dalam jangka waktu panjang. Selain itu hypnotherapy telah banyak diterapkan pada berbagai masalah psikologis baik depresi, kecemasan, maupun gangguan psikosomatik (Rakhmawati, 2014). Terapi hypnosis ini diterapkan pada pasien yang mengalami chronic sorrow, mengalami kesedihan yang mendalam, dan merasakan kehilangan fungsi tubuh. Melalui bimbingan terapis masalah chronic sorrow dapat meningkatkan kemampuan adaptasi dalam menghadapi penyakitnya.

\section{METODE PENELITIAN}

Desain penelitian menggunakan quasy eksperiment dengan pendekatan pre test - post test with control group. Penelitian ini dilaksanakan di RSUD Kabupaten Kediri pada bulan Mei 2019. Sampel adalah pasien hemodialisis yang mengalami chronic sorrow, terdiri dari 20 responden kelompok intervensi dan 20 responden kelompok kontrol, dengan purphosive sampling. Instrument untuk pengambilan data menggunakan intrumen baku kendall chronic sorrow.

$\begin{array}{lrr} & \text { Uji etik merupakan tahap } \\ \text { yang dilakukan } & \text { sebelum } \\ \text { pengambilan data. } & \text { Setelah } \\ \text { dinyatakan laik etik, } & \text { peneliti }\end{array}$ melakukan screening untuk memilih calon responden sesuai kriteria inklusi. Screening menggunakan Kendall Chronic Sorrow Instrument (KCSI) untuk memilih responden yang mengalami chronic sorrow. Pengambilan data diawali dengan melakukan informed consent kepada calon responden. Pada kelompok perlakuan dilakukan pre tes kemudian di berikan intervensi satu kali setiap individu kemudian dilakukan evaluasi setelah satu minggu. Kelompok control di lakukan pre tes dan setelah satu minggu dilakukan evalusi, tanpa perlakuan. Kemudian diuji beda menggunakan Wilcoxon Sign Rank $(\alpha=5 \%)$ untuk mengetahui perbedaan chronic sorrow sebelum dan sesudah intervensi pada kelompok perlakuan dan kelompok kontrol. Sedangkan untuk mengetahui perbedaan antara kelompok intervensi dan kelompok control digunakan uji statistic Mann Whitney $(\alpha=5 \%)$.

\section{HASIL}

Hasil penelitian terdiri dari data umum dan data khusus. Data umum disajikan dalam bentuk tabel tentang karakteristik responden (tabel 1) dan data khusus hasil analisis antara kelompok perlakuan dan kelompok kontrol. 
Table 1. Karakteristik Responden Penelitian, Mei 2019

\begin{tabular}{|c|c|c|c|c|c|c|}
\hline \multirow{2}{*}{ No } & \multirow{2}{*}{ Karakteristik } & \multirow{2}{*}{ Kategori } & \multicolumn{2}{|c|}{ Perlakuan } & \multicolumn{2}{|c|}{ Kontrol } \\
\hline & & & $\mathbf{N}$ & $\%$ & $\mathbf{N}$ & $\%$ \\
\hline \multirow[t]{3}{*}{1} & Usia & $31-40$ th & 3 & 15 & 7 & 35 \\
\hline & & $41-50$ th & 10 & 50 & 10 & 50 \\
\hline & & $>50$ th & 7 & 35 & 3 & 15 \\
\hline \multirow[t]{4}{*}{2} & Pendidikan & SD & 9 & 45 & 5 & 25 \\
\hline & & SMP & 3 & 15 & 7 & 35 \\
\hline & & SMA & 6 & 30 & 8 & 40 \\
\hline & & PT & 2 & 10 & 0 & 0 \\
\hline \multirow[t]{6}{*}{3} & Pekerjaan & PNS/Pensiunan & 2 & 10 & 1 & 5 \\
\hline & & Wiraswasta & 6 & 30 & 6 & 30 \\
\hline & & Petani & 2 & 10 & 4 & 20 \\
\hline & & Buruh Tani & 2 & 10 & 2 & 10 \\
\hline & & IRT/Tidak & 8 & 40 & 7 & 35 \\
\hline & & Bekerja & & & & \\
\hline \multirow[t]{2}{*}{4} & Jenis Kelamin & Laki laki & 11 & 55 & 9 & 45 \\
\hline & & Perempuan & 9 & 45 & 11 & 55 \\
\hline \multirow[t]{4}{*}{5} & Riwayat & Diebetes Mellitus & 6 & 30 & 8 & 40 \\
\hline & Penyakit & Hipertensi & 6 & 30 & 7 & 35 \\
\hline & & Gagal ginjal & 4 & 20 & 3 & 15 \\
\hline & & Tidak ada riwayat & 4 & 20 & 2 & 10 \\
\hline \multirow[t]{2}{*}{6} & Frekuensi HD & $4 \mathrm{x} /$ bulan & 1 & 0,5 & 0 & 0 \\
\hline & & $8 x /$ bulan & 19 & 95 & 20 & 100 \\
\hline \multirow[t]{3}{*}{7} & Lama HD & $\leq 1$ tahun & 10 & 50 & 8 & 40 \\
\hline & & 2-3 tahun & 8 & 40 & 8 & 40 \\
\hline & & $>3$ tahun & 2 & 10 & 4 & 20 \\
\hline
\end{tabular}

Sumber: Data Primer, Mei 2019

Tabel 1 menunjukkan karakteristik responden kelompok perlakuan, setengah responen $(50 \%)$ berusia 41 50 tahun, hampir setengah responden (45\%) berpendidikan sekolah dasar, hampir setengah responden $(40 \%)$ sebagai ibu rumah tangga atau tidak bekerja, sebagian besar responden $(55 \%)$ laki laki, riwayat penyakit hampir setengah responden $(30 \%)$ mempunyai riwayat penyakit diabetes mellitus atau hipertensi, hampir seluruhnya (95\%) frekuensi hemodialis 8 kali dalam satu bulan, dan lama hemodialisis setengah responden $(50 \%)$ kurang atau sama dengan satu tahun. Pada kelompok kontrol karakteristik responden setengah responen $(50 \%)$ berusia 41 50 tahun, hampir setengah responden (45\%) berpendidikan SMA, hampir setengah responden (35\%) sebagai ibu rumah tangga atau tidak bekerja, sebagian besar responden (55\%) perempuan, riwayat penyakit hampir setengan responden $(40 \%)$ diabetes mellitus, seluruhnya $(100 \%)$ frekuensi hemodialis 8 kali dalam satu bulan, dan lama hemodialisis hampir setengah responden $(50 \%)$ kurang atau sama dengan satu tahun dan 2 sampai 3 tahun. 
Tabel 2. Analisis Perbedaan Chronic Sorrow pada Kelompok Perlakuan Sebelum dan Sesudah dilakukan Hypnotherapy

\begin{tabular}{lllll}
\hline \multirow{2}{*}{ Kategori } & \multicolumn{2}{c}{ Sebelum } & \multicolumn{2}{c}{ Sesudah } \\
\cline { 2 - 5 } & $\mathrm{N}$ & $\%$ & $\mathrm{~N}$ & $\%$ \\
\hline Chronic Sorrow & 20 & 100 & 3 & 15 \\
\hline Tidak Chronic & 0 & 0 & 17 & 85 \\
Sorrow & & & \\
\hline p value= 0,000 & &
\end{tabular}

Hasil uji stastistik wilcoxon sign rank $\mathrm{p}=0,000 \quad(\mathrm{p}<0,005)$ artinya terdapat perbedaan chronic sorrow pre dan post hypnotherapy secara signifikan.

Tabel 3. Analisis Perbedaan Chronic Sorrow pada Kelompok Kontrol Sebelum dan Sesudah Intervensi

\begin{tabular}{llllc}
\hline \multirow{2}{*}{ Kategori } & \multicolumn{3}{c}{ Sebelum } & Sesudah \\
\cline { 2 - 5 } & $\mathrm{N}$ & $\%$ & $\mathrm{~N}$ & $\%$ \\
\hline Chronic Sorrow & 20 & 100 & 18 & 90 \\
\hline $\begin{array}{l}\text { Tidak Chronic } \\
\text { Sorrow }\end{array}$ & 0 & 0 & 2 & 10 \\
\hline$p$ value= 0,655 \\
\hline \multicolumn{4}{c}{ Sumber : Analisis data hasil penelitian, 2019 }
\end{tabular}

Tabel 3 menunjukkan uji stastistik wilcoxon sign rank $p$ value $=0,655$
( $\mathrm{p}>0,005)$ chronic sorrow sebelum dan sesudah tidak berbeda secara signifikan.

Tabel 4. Analisis Perbedaan Chronic Sorrow antara Kelompok Perlakuan dan Kelompok Kontrol Setelah Hypnotherapy

\begin{tabular}{|c|c|c|c|c|c|}
\hline \multirow[t]{3}{*}{ Kelompok } & \multicolumn{4}{|c|}{ Pengukuran } & \multirow[t]{3}{*}{$p$ value } \\
\hline & \multicolumn{2}{|c|}{ Sebelum } & \multicolumn{2}{|c|}{ Sesudah } & \\
\hline & $\begin{array}{c}\text { Chronic } \\
\text { sorrow }\end{array}$ & $\begin{array}{c}\text { Tidak } \\
\text { chronic } \\
\text { sorrow }\end{array}$ & $\begin{array}{l}\text { Chronic } \\
\text { sorrow }\end{array}$ & $\begin{array}{l}\text { Tidak } \\
\text { chronic } \\
\text { sorrow }\end{array}$ & \\
\hline Perlakuan & 20 & 0 & 3 & 17 & 0,000 \\
\hline Kontrol & 20 & 0 & 18 & 2 & 0,655 \\
\hline$p$ value & & 075 & & 0,000 & \\
\hline
\end{tabular}

Sumber : Analisis data hasil penelitian, 2019

Hasil uji statistik mann whitney pada tabel diatas $p$ value $=0,000(\mathrm{p}<0.05)$ artinya terdapat perbedaan chronic sorrow antara kelompok perlakuan dan kelompok kontrol setelah perlakuan. 


\section{PEMBAHASAN}

Hasil uji stastistik wilcoxon sign rank pada kelompok perlakuan diketahui terdapat perbedaan chronic sorrow pre dan post hypnotherapy. Chronic sorrow dilakukan pengukuran menggunakan Kendall Chronic Sorrow Instrument (KCSI) (Batchelor, 2017). Berdasarkan intrumen tersebut responden sering mengalami perasaan sedih, seolaholah baru saja menderita penyakit, merasakan keadaanya terpuruk karena penyakit yang diderita, dan adanya pikiran bahwa keadaannya saat ini tidak menguntungkan. Chronic sorrow terjadi diawali karena merasa kehilangan fungsi tubuh. Pengukuran chronic sorrow dilaksanakan sebelum tindakan hemodialisis.

Berdasarkan pengukuran terhadap 20 responden, semunya mengalami chronic sorrow dan hasil pos test menurun menjadi 3 responden yang mengalami chronic sorrow. Pengukuran post tes chronic sorrow dilakukan setelah satu minggu, untuk mengetahui frekuensi perasaan berduka yang dialami responden. Setelah dilakukan hypnotherapy, perasan sedih yang dialami responden frekuensinya menurun. Perasaan sedih yang mendalam tersimpan dalam otak bawah sadar. Hypnotherapy dilakukan untuk membimbing responden memasuki gerbang kesadaran agar terbuka melalui tahap relaksasi fisik dan relaksasi mental, kemudian dapat diberikan sugesti dan re-edukasi sesuai permasalahan yang dialami oleh responden. Maka dari itu perubahan perasaan chronic sorrow yang sering atau terus menerus dialami dapat terjadi perubahan frekuensi (Gunawan,
2007). Hypnotherapy dipengaruhi faktor internal, kemauan responden untuk menjadi lebih baik merupakan self hipnosis. Sesuai dengan penelitian (Enea Violeta, 2013) yang mengatakan motivasi datang dari keinginan untuk meningkatkan kualitas hidupnya.

Sedangkan pada kelompok kontrol, sesuai hasil pre test responden mengalami chronic sorrow seluruhnya $(100 \%)$ dan hasil post tes tanpa diberikan perlakuan hampir seluruhnya $(90 \%)$ mengalami chronic sorrow. Hasil uji stastistik menujukkan $p$ value $=0,655$ ( $>>0,05)$ chronic sorrow sebelum dan sesudah perlakuan tidak berbeda secara signifikan. Penderita gagal ginjal kronis dengan tindakan hemodialysis, mengalami kehilangan fungsi tubuh dan harus dilakukan tindakan hemodialysis dalam jangka waktu lama dan sangat mungkin seumur hidup.

$\begin{array}{lcr} & \text { Respon secara } & \text { psikologis } \\ \text { dalam menghadapi } & \begin{array}{r}\text { kenyataan } \\ \text { penderita }\end{array} \text { mengalami } & \text { tahap-tahap }\end{array}$ kehilangan, mulai dari penolakan, marah, tawar menawar, tahap depresi dan tahap penerimaan. Sesuai dengan hasil penelitian Zakiyah (2015) pada 10 partisipan yaitu ibu-ibu yang mempunyai pengalaman kehilangan. Akan tetapi apabila perasaan kehilangan ini berkepanjangan dan terjadi secara periodik maka penderita mengalami chronic sorrow. Pada kelompok kontrol responden tidak diberi perlakuan. Meskipun menujukkan hasil tidak ada perbedaan, tetapi $10 \%$ responden mengalami perubahan skor dari 18 menjadi 16. Artinya 2 orang responden mengalami perubahan dari terjadi chronic sorrow menjadi tidak mengalami chronic sorrow. Hal ini dialami oleh responden yang rentang 
waktu hemodialysis 2-3 tahun. Rentang waktu sakit membuat penderita lebih mudah beradaptasi dengan penyakitnya. Hal ini sesuai jurnal Maramis (2013) bahwa penderita gagal ginjal kronis yang dilakukan hemodialysis beberapa kali cenderung mengalami tingkat kecemasan dan stress yang lebih tinggi, dibandingkan dengan penderita yang banyak frekuensi tindakan hemodialysis.

Hasil analisis perbedaan antara kelompok perlakukan dan kontrol diketahui post tes kelompok perlakuan hampir seluruhnya (85\%) dan kelompok kontrol sebagian kecil ( 10\%) tidak mengalami chronic sorrow. Hasil uji statistik Mann Whitney diketahui $p$ value $=0,000$ $(\mathrm{p}<0.05)$ artinya terdapat perbedaan chronic sorrow antara kelompok perlakuan dan kelompok kontrol setelah perlakuan. Hal ini menunjukkan ada pengaruh hypnotherapy terhadap chronic sorrow.

Hypnotherapy dilakukan pada responden yang bersikap terbuka dan bersedia dibimbing untuk memasuki tahap-tahap kesadaran. Tujuan terapi ini menjangkau kesadaran pada tahap theta, agar responden dapat membuka critical factor. Kritikal faktor ini yang membatasi pikiran sadar dan bawah sadar. Dengan terbukanya Kritikal faktor responden diberikan re-edukasi dan sugesti untuk mensyukuri hidup yang diberikan Tuhan, menerima keadaan sakit dan mempunyai harapan dalam menjalani hidupnya. Hal ini berkesinambungan dengan hasil penelitian Rahayu (2019) tentang kehilangan yang dialami responden memerlukan penanganan yang efektif untuk menangani kesedihan sehingga menjadi lebih positif menjalani hidup. Maka dari itu responden dapat mengalami perubahan frekuensi chronic sorrow setelah perlakuan.

$$
\text { Pada dasarnya pikiran }
$$

manusia $80 \%$ dikendalikan oleh pikiran bawah sadar. Terapi ini dapat berpengaruh karena perasaan sedih yang mendalam dikendalikan oleh pikiran bawah sadar. Berdasarkan penelitian Flammer dan Bongartz dari universitas Konstanze di Jerman melakukan meta analisis dari berbagai penelitian tentang hypnotherapy, hasilnya dari 57 penelitian hypnotherapy mencapai 64\% keberhasilan dalam menangani masalah psikologi seperti kecemasan, depresi, emosi tidak stabil maupun kecemasan (Rakhmawati R, 2014).

Pada kelompok kontrol, 20 responden tidak diberikan intervensi. Responden membaca lembar balik yang sudah diberikan peneliti. Hasilnya menunjukkan tidak signifikan karena dengan membaca tidak menjangkau pikiran bawah sadar, sehingga skor chronic sorrow tidak ada perubahan yang signifikan.

\section{SIMPULAN}

Ada perbedaan chronic sorrow antara kelompok perlakuan dan kontrol setelah hypnotherapy .

\section{SARAN}

Bagi praktisi kesehatan disarankan agar menggunakan hypnotherapy sebagai salah satu cara mengatasi masalah psikologis. Bagi responden diharapkan dapat menerapkan self hypnosis dalam menjalani hidup sehari hari. 


\section{DAFTAR PUSTAKA}

Alligood, M. (2017). Pakar teori Keperawatan dan Karya mereka (8 ed.). (A. Y. Ibrahim, Trans.) Indonesia.

Anggraeni R., L. M. (2015). Restraint To Schizophrenic Family Member At Home: Family Experience In Kendal. (Pp. 400-407). Semarang: Jurusan Keperawatan, Fakultas Kedokteran. Retrieved Juli Senin, 2019, From Official URL:

Http://Keperawatan.Undip.A c.Id/Id/Jinc

Batchelor, L. L. (2017). The Lived Experiences Of Parents With Chronic Sorrow Who Are Caring For Children With A Chronic Medical Condition. University Of Texas At Tyler. Texas: Https://Scholarworks.Uttyler. Edu/Nursing_Grad.

Darmawati, I. (2017, Juli). Literatur Review : Aplikasi Terapi Han (Hipnotis, Aktifitas Fisik, Nutrisi) Pada Keluarga Anak Usia Sekolah Dengan Obesitas. Jurnal Keperawatan Komprehensif, 3, 86-93. Https://Doi.Org/10.33755/Jkk .V3i2.89

Elman, D. (1977). Hynotherapy. Los Angeles: Glendale: Westwood Publising Co.

Enea Violeta, I. D. (2013). Cognitive Hypnotherapy In Addressing The Posttraumatic Stress Disorder. Procedia - Social And Behavioral Sciences,78, 36-40.

Https://Doi.Org/10.1016/J.Sb spro.2013.04.246
Priastana, I Ketut Andika, Haryanto, J., \& Suprajitno, S. 2018. Peran Dukungan Sosial Keluarga terhadap Berduka Kronis pada Lansia yang Mengalami Kehilangan Pasangan dalam Budaya Pakurenan. Indonesian Jornal of Health Research. 1(01): 20-26.

Doi: https://doi.org/10.32805/ijhr.2 018.1.18.

Rizky, F., Mugianti, S., Sunarno, I., \& Winarni.Sri. (2016). The quality Life of The Renal Failure Patient Undergo Hemodialysis. Journal of Ners and Midwifery, 118122. doi:DOI: 10.26699/jnk.v3i2.ART

Gunawan, A. W. (2007). Hypnotherapy, The Art Of Subconcious Restructuring. Jakarta: PT Garmedia Pustaka Utama,.

Holdevici Irina, C. B. (2013). Hypnosis In The Treatment Of Patients With Anxiety Disorders. Procedia- Social and Behavior Science, 471475.

Doi: 10.1016/J.Sbspro.2013.04.333

Holdevici Irina, C. B. (2013). The Role Of Ericksonian Hypnosis In Reducing Essential And Secondary Hypertension. ProcediaSocial and Behavioral Science, 461-465. Doi:10.1016/J.Sbspro.2013.0 4.331

Irianto Ady DS, K. S. (2014). Pengaruh Hipnoterapi Terhadap Penurunan Tingkat Kecemasan Pada Pasien yang menjalani Kemoterapi Di RS Telogorejo Semarang, Jurnal Ilmu Keperawatan Dan Kebidanan, 1-10. Retrieved From Http://112.78.40.115/E- 
Journal/Index.Php/Ilmukeper

awatan/Article/View/253/278

Kartika Nurmalia Anggraeni, B. S.

(2012, Juli). Hubungan

Dukungan Keluarga Dengan

Tingkat Depresi Pada Pasien

Yang Menjalani Terapi

Hemodialisa Di Unit

Hemodialisa Rumah Sakit

Tentara Dr Soedjono

Magelang. Jurnal

Keperawatan Soedirman,

12(2), 109-117

Http://Dx.Doi.Org/10.20884/

1.Jks.2017.12.2.692

Keputusan Menteri Kesehatan RI

NOMOR

812/Menkes/SK/VII/2007

Tentang Kebijakan Perawatan Paliatif

Mujahidah Z, H. A. (2015, November). Pengalaman Kehilangan Dan Berduka Pada Ibu Yang Mengalami Kematian Bayi Di Depok. Jurnal Keperawatan Jiwa, 3(2), 124-136. Https://Doi.Org/10.26714/Jkj. 3.2.2015.40-52

Maramis, V. N., \& Mariyanti, S. (2013). GAMBARAN MAKNA HIDUP PASIEN GAGAL GINJAL KRONIK YANG MENJALANI HEMODIALISA. Jurnal Psikologi, 1-13. Retrieved from

https://digilib.esaunggul.ac.id /public/UEU-Journal-4423158-468-1-SM.pdf

Nugraha, D. A. (2018, JanuaryFebruary). Ffect Of HypnoPressure On Anxiety In Patients With Cardiovascular Disorder. Belitung Nursing Journal, 4(1), 39-44. Https://Doi.Org/10.33546/Bn j.348
Nurchayati, S. (2016). Hubungan Kecemasan Dengan Kualitas Hidup Pasien Penyakit Ginjal Kronik Yang Menjalani Hemodialisis. Jurnal Keperawatan Jiwa, 4(1), 1-6, Https://Doi.Org/10.26714/Jkj. 4.1.2016.1-6

NANDA-I, Nursing Diagnosis Definition and Clasification, 2018-2020

Rahayu, D. S. (2019). Chronic Sorrow Theory Application" To Overcome The Feeling Of Loss Due To Infant Mortality In Post-Partum Women. Maternity Care And Reproductive Health, 2(1), 100-106. Retrieved From Http://Www.Mcrhjournal.Or. Id/Index.Php/Jmcrh/Article/V iew/70/53

Rakhmawati R, P. K. (2014, Juli). Metode Keperawatan Komplementer Hipnoterapi Untuk Menurunkan Efek Stress Pasca Trauma Tingkat Sedang Pada Fase Rehabilitasi Sistem Penanggulangan Kegawatdaruratan Terpadu (SPGDT). P-ISSN : 20863071 | E-ISSN : 2443-0900, $5, \quad 178 \quad-\quad 184$. Https://Doi.Org/10.22219/Jk. V5i2.2347

Sakitri, G. (2018). Pengaruh Intradialytic Exercise Terhadap Fatigue, Kadar Hemoglobin Dan Tekanan Darah Pasien Hemodialisa Di Rsup Dr. Soeradji Tirtonegoro Klaten. Yogyakarta: Universitas Muhamadiyah Yogyakarta. Retrieved From Http://Repository.Umy.Ac.Id/ Handle/123456789/20856 
Sari, S. A. (2017). Gambaran Tingkat Depresi pada Pasien Gagal Ginjal Kronis yang menjalani Terapi Hemodialisis Di rumah Sakit Umum Daerah Wates,Universitas Jenderal Achmad Yani Yogyakarta., Yogyakarta. Retrieved From Http://Repository.Unjaya.Ac. $\mathrm{Id} / \mathrm{Id} /$ Eprint/2282

Simandalahi, T. (2019). Dukungan Keluarga Dan Lama Dialisis Sebagai Variabel Yang Berhubungan Dengan Kepatuhan Pembatasan Cairan Pasien Gagal Ginjal Kronik. NERS Jurnal Keperawatan, 15(1). Https://Doi.Org/10.25077/Nj k.15.1.2535.2019

Suparti Sri, N. S. (2018, 2018). Hubungan Depresi Dengan Fatigue Pada Pasien Hemodialisis. Jounal of Health Studies, 2(1), 63-75. Doi:DOAJ: Http://Doaj.Org/Toc/25493353

Supriyadi -, W. -,. (2011). Tingkat Kualitas Hidup Pasien Gagal Ginjal Kronik Terapi Hemodialisis. Jurnal Kesehatan Masyarakat, 6(2), 107-112. Https://Doi.Org/10.15294/Ke mas.V6i2.1760

Wati, S. H. (2017). Hypnodialysis For Anxiety Relief And Adherence To Medication, Kidney Diet And Fluid Intake In Patients With. Belitung Nursing Journal, 3(6), 712721.

Https://Doi.Org/10.33546/Bn j.306 